\title{
Effect of an anti-androgen on testicular descent and inguinal closure in a marsupial, the tammar wallaby (Macropus eugenii)
}

\author{
D. Coveney ${ }^{1 *}$, G. Shaw ${ }^{1}$, J. M. Hutson ${ }^{2,3}$ and M. B. Renfree ${ }^{1}$ \\ ${ }^{1}$ Department of Zoology, University of Melbourne, Victoria 3010, Australia; ${ }^{2}$ Department \\ of Pediatrics, University of Melbourne, Victoria 3010, Australia; and ${ }^{3}$ Murdoch Children's \\ Research Institute, Royal Children's Hospital, Parkville, Victoria 3052, Australia
}

\begin{abstract}
Androgens are essential for testicular descent in eutherian mammals, but little is known about its hormonal control in marsupials. This study reports the effects of daily treatment with the anti-androgen flutamide $\left(10 \mathrm{mg} \mathrm{kg}^{-1}\right)$ from day 9 to day 75 after birth on the descent of the testis and inguinal closure in tammar wallabies. By day 75 after birth, the testes of control males had descended and the prostate gland was well developed. The testes of all flutamidetreated males had passed through the inguinal canal and were situated in the base of the scrotum. Three of the nine flutamide-treated males had unilateral inguinal hernias. The size of the inguinal canal, regardless of whether a hernia was present, was significantly wider than that of control males. Development of the prostate gland was significantly inhibited. By day 75 after birth, the phallus was significantly longer in control males than in females,
\end{abstract}

whereas the phallus of flutamide-treated males was similar to that of control females. In flutamide-treated males, the lumbar 1 dorsal root ganglia was feminized and significantly fewer cell bodies expressed calcitonin gene-related peptide. As the anti-androgen treatment resulted in a reduction in the number of calcitonin gene-related peptide-positive cell bodies in the dorsal root ganglion supplying the genitofemoral nerve, the process of inguinal closure in tammar wallabies may be mediated by calcitonin gene-related peptide via the genitofemoral nerve, as indicated in humans. Flutamide treatment inhibited development of the prostate gland and phallus, which are both androgen-dependent structures, but it did not affect the normal descent of the testis, indicating that testicular descent can proceed when the action of androgens is blocked.

\section{Introduction}

Testicular descent is a complex process, in which hormonal and mechanical factors induce the testis to migrate from the abdomen through the abdominal wall and into the scrotum (Hutson, 1985). Testicular descent occurs in two phases: (i) transabdominal migration, in which the testis migrates caudally from below the kidney to the internal inguinal ring and (ii) inguinoscrotal migration, in which the testis descends through the inguinal canal and into the scrotum. Both phases require male-specific differentiation of the cranial suspensory ligament and the gubernaculum. Transabdominal migration involves the swelling and outgrowth of the gubernaculum and the regression of the cranial suspensory ligament, whereas inguinoscrotal migration is associated with the subsequent thinning and elongation of the gubernaculum (Hutson et al., 1997).

Androgens appear to play an important role in testicular descent, as this process fails in animals and humans with androgen resistance syndromes (Hutson, 1986; Hutson et al., 1994). However, there is variation in the degree of testicular descent, the specific target tissues and the time when andro-

*Present address: Department of Cell Biology, Duke University Medical Center, Durham, NC 27710, USA

Email: d.coveney@cellbiol.duke.edu gens are required (Barthold et al., 2000). During transabdominal migration, androgens appear to play only a minor role. In humans and animals with androgen resistance (Wensing, 1973; Wensing et al., 1975; Fentener van Vlissingen et al., 1988; Barthold et al., 2000) or after treatment with the androgen receptor inhibitor flutamide (Shono et al., 1994; Cain et al., 1995), the gubernaculum swells and transabdominal migration occurs. However, androgens are required for regression of the cranial suspensory ligament, as the ligament fails to regress in testicular feminized (tfm) males or male rodent fetuses exposed to anti-androgens (van der Schoot and Elger, 1992; Lee and Hutson, 1999). Testosterone treatment of female rodent fetuses induces the regression of the cranial suspensory ligament allowing the ovaries to move to a lower position in the abdomen (van der Schoot, 1993; Emmen et al., 1998; Lee and Hutson, 1999). Androgens also affect inguinoscrotal descent. Regression and migration of the gubernaculum is inhibited by prenatal exposure to antiandrogens (Husmann and McPhaul, 1991a; Shono et al., 1994; Cain et al., 1995) and males with androgen resistance syndromes predominantly have maldescended testes situated distal to the internal inguinal ring (Hutson, 1986).

In humans, the process of testicular descent is completed by closure of the inguinal canal. The inguinal canal closes by the fusion of the epithelium of the processus vaginalis 
(Clarnette and Hutson, 1999). Failure of this closure predisposes to inguinal hernia or scrotal hydrocele (Clarnette and Hutson, 1999). Androgens also appear to be involved in inguinal closure, as humans with defective androgen receptors have patent inguinal canals (Atwell, 1961, 1962).

Although it is accepted that inguinoscrotal descent and inguinal closure are mediated by androgens, the absence of androgen receptors in the gubernaculum and hernia sacs indicate an indirect mechanism of androgen action (Heyns and Pape, 1991; Husmann and McPhaul, 1991b; Bentvelsen and George, 1993; Johansen and Klein, 1993). It appears that androgens act via the genitofemoral nerve that innervates the gubernaculum (Tayakkanonta, 1963). Supportive evidence for this hypothesis comes from observations that denervation or abnormalities in the development of the genitofemoral nerve result in inguinal testes and inguinal hernias (Lewis, 1948; Beasley and Hutson, 1987; Hutson et al., 1988a; Clarnette and Hutson, 1996; Clarnette et al., 1996). Larkins et al. (1991) proposed that androgens masculinize the genitofemoral nerve, increasing the concentration of its neuropeptide, calcitonin gene-related peptide (CGRP). CGRP is then released distal to the gubernaculum inducing testicular descent and inguinal closure via mechanisms that remain unclear.

As in eutherian mammals, androgens are responsible for the differentiation of the urogenital system of the marsupial male. Testosterone concentrations increase in the testes by day 2 after birth and remain high until day 45 after birth, before decreasing to concentrations observed in the developing ovary (Renfree et al., 1992). This increase encompasses the initiation of prostatic development at about day 25 after birth, but penile differentiation does not occur until day 80 after birth (Shaw et al., 1988; Renfree et al., 1996; Butler et al., 1999). Although penile development occurs after concentrations of testicular androgens have decreased, it is clear that its differentiation is androgen-dependent. Prostatic and penile growth requires the presence of the testis, as castration inhibits their development and testes transplanted into female pouch young at day 10 after birth induce phallic and urogenital sinus virilization (TyndaleBiscoe and Hinds, 1989). In addition, the urogenital sinus and phallus are sensitive to androgens as administration of testosterone and dihydrotestosterone causes prostatic and penile development in females (Burns, 1939a,b,c; Shaw et al., 1988; Ryhorchuk et al., 1997; Leihy et al., 2001). Prostatic development is inhibited in male pouch young treated with an anti-androgen or a $5 \alpha$-reductase inhibitor, indicating that dihydrotestosterone or another $5 \alpha$-reduced androgen is responsible for virilization of the urogenital tissues (Lucas et al., 1997; Ryhorchuk et al., 1997).

Although there is no detectable sexual dimorphism in the plasma of either testosterone or dihydrotestosterone during the period of sexual differentiation (Wilson et al., 1999), plasma $5 \alpha$-androstane- $3 \alpha, 17 \beta$-diol (adiol) concentrations are three times higher in developing male pouch young than in female pouch young, and significantly higher than concentrations in adult males (Shaw et al., 2000). The urogenital sinus and phallus are extremely sensitive to adiol administration, which induces complete penile and prostatic development in female young (Shaw et al., 2000; Leihy et al., 2001, 2002).

Testicular descent in tammar wallabies takes place in two phases. Transabdominal migration occurs between day 10 and day 25 after birth and inguinoscrotal migration between day 25 and day 60 after birth (Hutson et al., 1988b; Renfree et al., 1996). However, unlike eutherian mammals, the scrotum develops cranial to the phallus (Tyndale-Biscoe and Renfree, 1987; Griffiths et al., 1993) and the scrotum, gubernaculum and processus vaginalis develop before testicular differentiation (O et al., 1988; Renfree and Short, 1988; Renfree et al., 1996). The role of androgens in the process of testicular descent in tammar wallabies is unclear. Testosterone administration to developing female pouch young had no effect on ovarian position (Shaw et al., 1988). Furthermore, gubernacular swelling and transabdominal descent occur in male pouch young treated with flutamide from day 9 to day 45 after birth (Lucas et al., 1997).

One of the most interesting aspects of testicular descent in tammar wallabies is that, as in humans, the inguinal canal goes through a process of closure after the descent of the testis as a result of a decrease in the size of the processus vaginalis, which is completed by day 60 after birth (Coveney et al., 2002a). Closure of the inguinal canal appears to be androgen-dependent as flutamide-treated male pouch young had inguinal hernias (Lucas et al., 1997). Treatment of male pouch young with oestradiol benzoate from day 10 to day 25 after birth and from day 0 to day 25 after birth resulted in patent inguinal canals and inguinal hernias, indicating that, as in humans, androgens play an important role in inguinal development (Coveney et al., 2002a).

The aim of the present study was first to define the role of androgens in the processes of testicular descent and inguinal closure in the tammar wallaby. Pouch young were treated with flutamide for a long period that encompassed both testicular descent and inguinal closure. The genitofemoral nerve and CGRP appear to have an important role in both the descent of the testis and inguinal closure in humans. In addition, the second aim was to identify whether the genitofemoral nerve had CGRP-positive neurones and whether these were sensitive to androgens.

\section{Materials and Methods}

\section{Animals}

Tammar wallabies (Macropus eugenii) obtained from Kangaroo Island were kept in open grassy yards in our breeding colony in Melbourne, Victoria, Australia. Food was supplemented with lucerne cubes, oats and fresh vegetables. Removal of pouch young (RPY) during the breeding season reactivates the diapausing embryo and birth occurs at day $26.5 \pm 0.4$ of gestation (Tyndale-Biscoe and Renfree, 1987). Animals were checked for birth each day from day 24 after RPY and the day on which the pouch 
young were first observed was termed day 0 after birth. The pouch young were examined with an otoscope to determine sex by the presence of scrotal bulges (male) or mammary primordia (females) (O et al., 1988). Ages of older pouch young were determined from known headlength charts (Poole et al., 1991)

All animal handling and experiments conformed to the Australian National Health and Medical Research Council's (1997) guidelines and were approved by Institutional Animal Experimentation Ethics Committees.

\section{Administration of flutamide}

Male pouch young $(n=9)$ were treated with $10 \mathrm{mg}$ flutamide $\quad \mathrm{kg}^{-1}$ (2-methyl- $\mathrm{N}$-[4-nitro-3-(trifluormethyl)phenyl]propanamide) (Sigma-Aldrich, Castle Hill, NSW) dissolved in $100 \%$ alcohol $\left(40 \mathrm{mg} \mathrm{ml}^{-1}\right)$ and diluted to a final concentration of $10 \mathrm{mg} \mathrm{ml}^{-1}$ in $0.4 \%(\mathrm{w} / \mathrm{v})$ methyl cellulose solution from day 9 to day 75 after birth. Males were treated orally by inserting a polyethylene catheter tube between the teat and the mouth of the pouch young (Jurgelski, 1971; Shaw et al., 1988). The flutamide solution was vortexed before it was drawn up into the catheter to ensure even distribution of the suspended flutamide crystals. Untreated control male $(n=6)$ and female $(n=6)$ tammar wallabies were observed during the same treatment period.

At day 75 after birth, the young were killed by an i.p. overdose of sodium pentobarbitone $\left(60 \mathrm{mg} \mathrm{ml}^{-1}\right)$. The external genitalia were examined, and in particular the presence or absence of testes in the inguinal canal and inguinal hernias were noted. The length of the phallus, from the base of the genital tubercle to the tip of the external genitalia, and the diameter of the genital tubercle were measured as described by Butler et al. (1999) and Leihy et al. (2002). The inguinal canals and testes were removed and fixed with either $4 \%(\mathrm{w} / \mathrm{v})$ paraformaldehyde or Zamboni's fixative (Humason, 1962) for cytokeratin immunohistochemistry. The dorsal root ganglia from thorax 12 (T12) to lumbar 3 (L3) vertebrae were fixed in Zamboni's fixative for CGRP immunohistochemistry. The prostate glands from control and flutamide-treated tammar pouch young were fixed in $10 \%$ neutral buffered formalin, embedded in paraffin wax, cut into serial sections $(5 \mu \mathrm{m}$ in thickness), and stained with Harris' haematoxylin and Putt's eosin (Humason, 1962).

\section{Retrograde labelling with 4',6-diamidino-2- phenylindole, dihydrochloride (DAPI)}

DAPI retrograde labelling of male and female pouch young at day 65 after birth (male, $n=1$; female, $n=1$ ) and at day 75 after birth (male, $n=6$; female, $n=6$ ) was conducted as described for rats (Larkins et al., 1991). The psoas muscle was exposed by a small incision in the retroperitoneal mesentery, and the genitofemoral nerve was identified in the ventral surface of the psoas muscle. The genitofemoral nerve originates from the L1 and L2 vertebrae, running ventrally to the ventral surface to the psoas major muscle (Fig. 1). From there, the nerve extends posteriorly, lateral to the psoas minor, passing under the ureter and vas deferens, over the iliac vessels, entering the inguinal canal along its dorsal wall, and continuing dorsally to the scrotum (Fig. 1).

The genitofemoral nerve was transected over the psoas muscle and DAPI crystals (Sigma-Aldrich) placed on the cut. After $48 \mathrm{~h}$, the pouch young were anaesthetized with halothane and perfused with ice-cold 0.01 mol PBS I-1 $(\mathrm{pH} 7.4)$ and Zamboni's fixative. The dorsal root ganglia and the spinal cord from T12 to L3 were removed and processed for CGRP immunofluorescence. Additional dorsal root ganglia from one day 65 , one day 75 and one day 100 male pouch young tammar were treated as described below for CGRP immunofluorescence.

\section{Cytokeratin immunofluorescence}

Inguinal canals were fixed in either $4 \%$ paraformaldehyde or Zamboni's fixative for $24 \mathrm{~h}$ at $4{ }^{\circ} \mathrm{C}$, washed in $0.01 \mathrm{~mol} \mathrm{PBS} \mathrm{I}^{-1}$ ( $\left.\mathrm{pH} 7.4\right)$, stored in $30 \%(\mathrm{w} / \mathrm{v})$ sucrose dissolved in $0.01 \mathrm{~mol} \mathrm{PBS} \mathrm{I}^{-1}$ ( $\mathrm{pH} \mathrm{7.4)} \mathrm{for} 1-7$ days at $4{ }^{\circ} \mathrm{C}$, frozen in Tissue-Tek OCT cryomountant (Miles Laboratories, Melbourne, Victoria) and the blocks stored at $-80^{\circ} \mathrm{C}$ until sectioning. Tissue sections were cut at intervals of $10 \mu \mathrm{m}$ on a Reichert-Jung 3CM3000 cryostat (Leica, Hawthorn East, Victoria) and mounted on superfrost slides (Grale Scientific, Ringwood, Victoria). Tissue sections were air-dried for at least $1 \mathrm{~h}$ at room temperature, washed in $0.01 \mathrm{~mol}^{\mathrm{PBS}} \mathrm{I}^{-1}$ (pH 7.4), post-fixed in ice cold $100 \%$ acetone and washed in 0.01 mol PBS $\mathrm{I}^{-1}(\mathrm{pH} 7.4)$. Subsequently sections were incubated with $0.5 \%$ BSA dissolved in 0.01 mol PBS I-1 ( $\mathrm{pH}$ 7.4) for $30 \mathrm{~min}$ at room temperature to decrease nonspecific binding.

Polyclonal rabbit anti-bovine cytokeratin antibody (Cat. No. Z0622; DAKO, Botany, NSW) was used to immunolocalize cytokeratin in the tammar wallaby tissue. WWS was raised against cytokeratin subunits: 58 kDa (cytokeratin 5), 56 kDa (cytokeratin 11), 52 kDa (cytokeratin 8), 60 kDa (cytokeratin 4), $51 \mathrm{kDa}$ (cytokeratin 14-15) and $48 \mathrm{kDa}$ (cytokeratin 16). This cytokeratin antibody recognizes a wide spectrum of cytokeratin subunits from a variety of species including mice, rats and humans.

The cytokeratin antibody was used at a dilution of $1: 800$. A stock solution of $0.1 \%$ BSA dissolved in 0.01 mol PBS I-1 ( $\mathrm{pH}$ 7.4) was used to dilute all reagents. Tissue sections were incubated with primary antibodies for $24 \mathrm{~h}$ at $4^{\circ} \mathrm{C}$. After incubation with primary antibody, sections were washed in $0.01 \mathrm{~mol} \mathrm{PBS} \mathrm{I}^{-1}$ ( $\left.\mathrm{pH} 7.4\right)$ and incubated with secondary antibody (goat anti-rabbit immunoglobulinsbiotinylated; DAKO) at a dilution of 1: 400 for $1 \mathrm{~h}$ at room temperature. Sections were then washed in $0.01 \mathrm{~mol} \mathrm{PBS} \mathrm{I}^{-1}$ (pH 7.4) and incubated with avidin-biotin complex (Vectastain ABC Kit; Vecta Laboratories, Camperdown, NSW) at a dilution of 1: 400 for $30 \mathrm{~min}$ at room temperature to amplify the final protein signal. Sections were washed in 

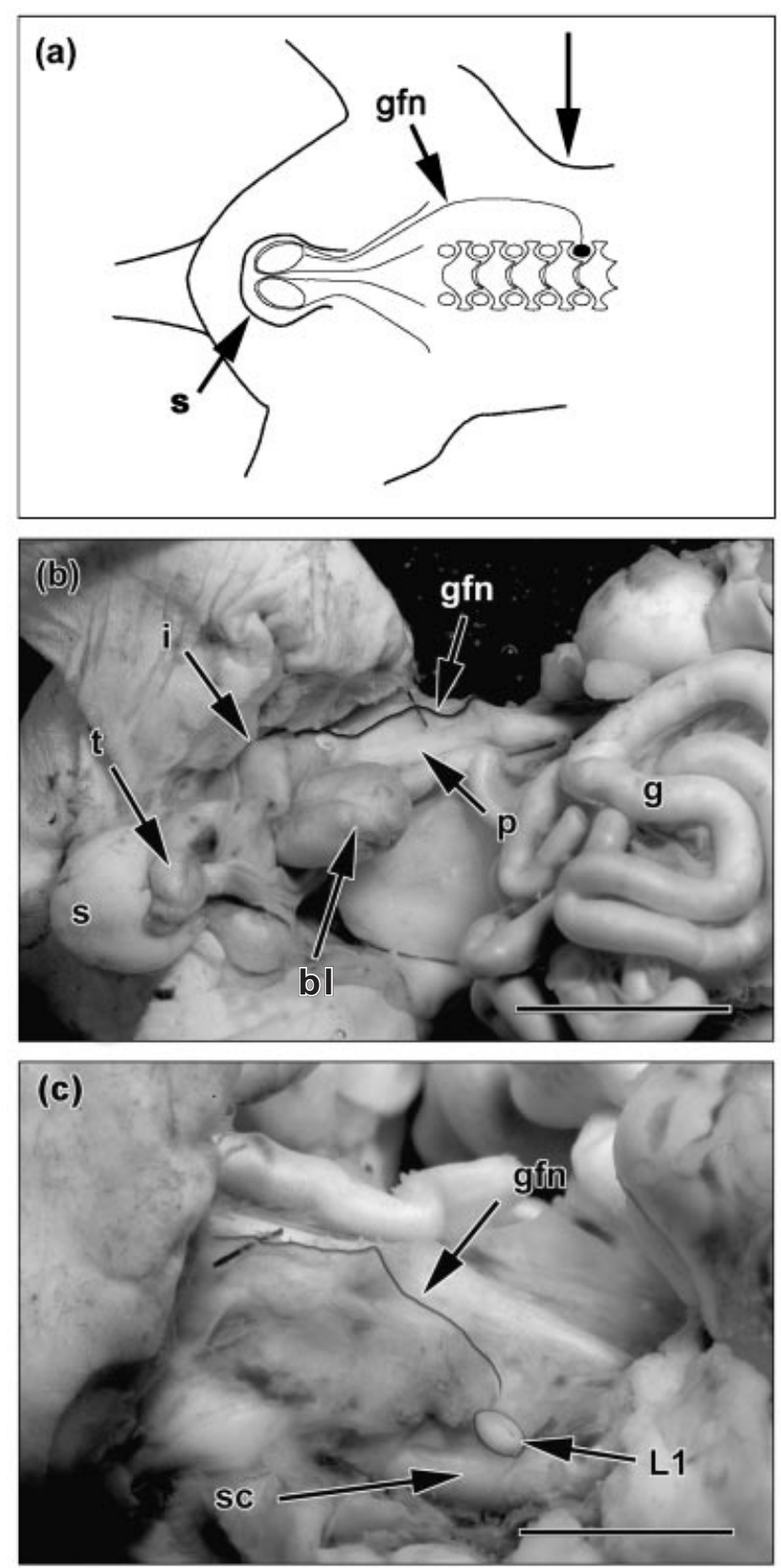

Fig. 1. The abdominal cavity of a male pouch young tammar wallaby at day 75 after birth. (a) A schematic diagram of the ventral view seen in (b) and the unlabelled arrow identifies the sagittal view seen in (c). (b) Ventral view with the intestine (g) displaced cranially to show the relative position of the genitofemoral nerve (gfn) and inguinal canal (i). The genitofemoral nerve (digitally highlighted) is positioned on the ventral surface of the psoas muscle (p), passes lateral to the bladder (bl) and enters the inguinal canal on its dorsal aspect. The testis (t) is situated within the scrotum (s). (c) Sagittal view of the abdomen in which the lateral portion of the psoas muscle has been removed to show the entry of the genitofemoral nerve into the lumbar 1 dorsal root ganglia (L1) and spinal cord (sc). Scale bars represent (b) $12 \mathrm{~mm}$ and (c) $6 \mathrm{~mm}$.

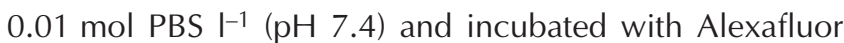
488 (Molecular Probes, Sydney, NSW) at a dilution of 1: 400 for $40 \mathrm{~min}$ at room temperature. Sections were then washed in $0.01 \mathrm{~mol} \mathrm{PBS}^{-1}$ ( $\left.\mathrm{pH} 7.4\right)$, mounted with Mowiol 4-88 (Hoechst, Frankfurt) and stored in the dark at $4^{\circ} \mathrm{C}$ for at least $2 \mathrm{~h}$ before viewing. Sections were examined using a Biorad confocal laser equipped Zeiss Axiovert microscope system using a $488 \mathrm{~nm}$ wavelength excitation laser.

\section{CGRP immunofluorescence}

Dorsal root ganglia and spinal cords were fixed in Zamboni's fixative for $24 \mathrm{~h}$ at $4^{\circ} \mathrm{C}$, cleared in $100 \%$ dimethylsulphoxide (DMSO) (Sigma-Aldrich) for $10 \mathrm{~min}$, washed in $0.01 \mathrm{~mol} \mathrm{PBS}^{-1}(\mathrm{pH} 7.4)$ and stored in $30 \%$ sucrose for $1-7$ days at $4{ }^{\circ} \mathrm{C}$. Specimens were then frozen in Tissue-Tek OCT (Miles Laboratories, Melbourne, Victoria) and stored at $-80^{\circ} \mathrm{C}$ until sectioning. Tissue sections were cut at intervals of $20 \mu \mathrm{m}$ on a Reichert-Jung 3CM3000 cryostat (Leica, Hawthorn East, Victoria) and mounted on superfrost slides (Grale Scientific, Ringwood, Victoria). A stock solution of $0.1 \%$ BSA dissolved in 0.01 mol PBS $\left.\right|^{-1}$ $(\mathrm{pH}$ 7.4) was used to dilute the reagents. Tissue sections were air-dried for at least $1 \mathrm{~h}$ at room temperature, washed in $0.01 \mathrm{~mol} \mathrm{PBS}^{-1}(\mathrm{pH} \mathrm{7.4)}$ and incubated in $10 \%$ normal pig serum for $30 \mathrm{~min}$ at room temperature to block nonspecific binding.

CGRP was localized in the dorsal root ganglia of tammar wallabies by the use of a polyclonal rabbit anti-rat CGRP antibody (Cat. No. AB1971; Amrad Biotech, Victoria) that recognizes $\alpha$-CGRP in a number of different species, including rodents, cats and pigs. Tissue sections were incubated with AB1971 at a dilution of 1:2000 for $24 \mathrm{~h}$ at room temperature, washed in $0.01 \mathrm{~mol} \mathrm{PBS} \mathrm{I}^{-1}(\mathrm{pH} \mathrm{7.4)}$ and incubated with a secondary antibody at a dilution of 1:400 (pig anti-rabbit immunoglobulins:FITC; DAKO) for $1 \mathrm{~h}$ at room temperature. After incubation, the sections were washed in $0.01 \mathrm{~mol}^{\mathrm{PBS}} \mathrm{I}^{-1}$ ( $\mathrm{pH}$ 7.4), mounted with Mowiol 4-88 (Hoechst) and stored in the dark at $4^{\circ} \mathrm{C}$ for a least $2 \mathrm{~h}$ before viewing. Sections were examined under a Biorad confocal laser microscope and were excited with a $488 \mathrm{~nm}$ wavelength excitation laser.

\section{Quantitation of CGRP cell bodies}

The blocks containing the dorsal root ganglia from control male $(n=2)$, control female $(n=2)$ and flutamide-treated male $(n=2)$ tammar wallabies were cut into serial sections and every tenth dorsal root ganglia was stained with anti-rat CGRP antibody. Sections were scanned on a Biorad confocal laser microscope with a $488 \mathrm{~nm}$ wavelength excitation laser using equally spaced optical sections through the thickness of the tissue ( $Z$ stacks). Only dorsal root ganglia cells that were clearly CGRP positive were counted.

\section{Measurements of the processus vaginalis}

Inguinal canals from control male $(n=3)$ and flutamidetreated male pouch young with $(n=2)$ and without hernias 

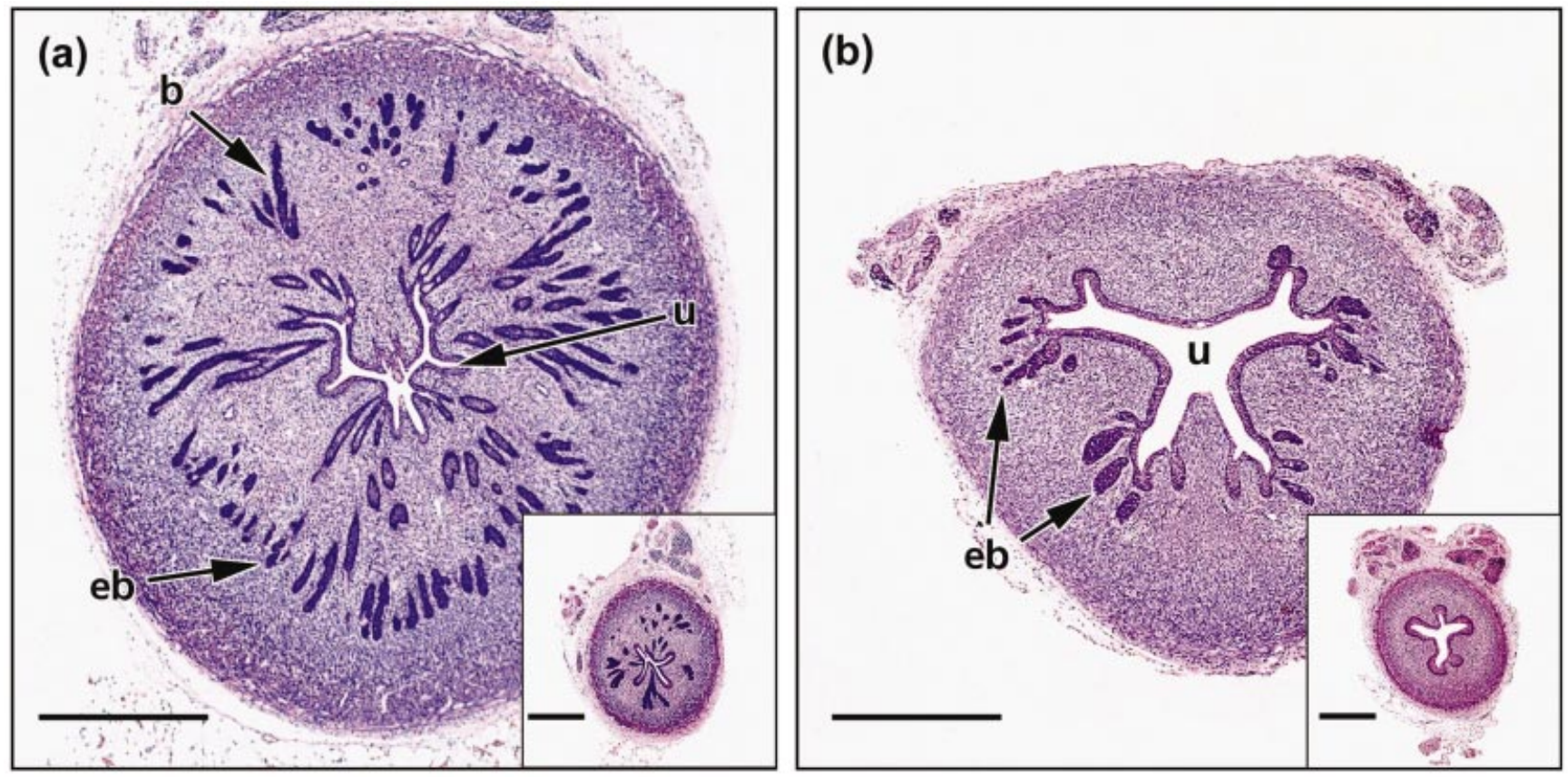

Fig. 2. (a) The control prostate gland of a tammar wallaby had developing epithelial buds (eb) projecting into the mesenchyme from the urethra (u). Epithelial buds were present in both the anterior and posterior (inset) portions of the prostate gland. (b) The prostate gland of a flutamide-treated male tammar wallaby had a significantly smaller volume and number of epithelial buds in the mesenchyme than controls. Epithelial buds were absent from the posterior portion of the prostate gland (inset). Scale bars represent $500 \mu \mathrm{m}$.

$(n=2)$ were cut into serial sections and stained for cytokeratin. Ten serial sections were cut through the smallest diameter of the inguinal canal and were used for measurements. Sections were digitized using the confocal microscope and the perimeter of the processus vaginalis was determined using the Sigma-Scan programme. The smallest perimeter measurement from each canal was used for comparisons between treatment groups.

\section{Statistical analysis}

Processus vaginalis measurements and counts of CGRPpositive cell bodies between flutamide-treated and control male groups were compared using 2-sample $t$ tests. Lengths of the phalluses of control male, control female and flutamidetreated male pouch young were compared using ANOVA with between-group differences assessed by Tukey's test. Data are presented as mean \pm SEM.

\section{Results}

\section{Location and morphology of the testes}

The testes of all control males were visible through the skin of the scrotum. The testes of all flutamide-treated males were situated within the scrotum, which was the same size as that of the controls (width: $6.8 \pm 0.29 \mathrm{~mm}$ versus $6.1 \pm 0.55 \mathrm{~mm}$; length: $9.6 \pm 0.27 \mathrm{~mm}$ versus $9.0 \pm 0.67 \mathrm{~mm} ; P>0.05$ treated versus control).

Testes of control and flutamide-treated males were histologically indistinguishable. The testes contained numerous seminiferous cords that contained Sertoli and germ cells. Sertoli cells had nuclei aligned against the basement membrane and their cytoplasm projecting into the centre of the cord. Germ cells were situated in the centre of the cords and were in interphase. The seminiferous cords were surrounded by the interstitium which consisted of blood vessels, Leydig cells, peritubular cells and connective tissue. The tunica albuginia consisted of a thick band of connective tissue under a squamous surface epithelium.

\section{Wolffian and Müllerian ducts}

In control and flutamide-treated male tammar wallabies, the Wolffian duct exited the urogenital sinus and curved into the internal inguinal ring ventral to the spermatic blood vessels. The Wolffian duct had differentiated into the vas deferens and epididymis and there were no obvious signs of abnormalities. There were no signs of the Müllerian duct adjacent to the vas deferens or epididymis in any animals.

\section{Morphology of the prostate gland}

The prostate glands of control males were well developed, and epithelial buds projected ventrally, dorsally and laterally from the urethra into the surrounding mesenchyme (Fig. 2a). In the cranial portion of the prostate gland, buds were isolated in the mesenchyme and some were forming patent epithelial glands, but posteriorly fewer non-patent buds were present within the mesenchyme. The epithelial buds had stratified squamous epithelium, with eosinophilic 


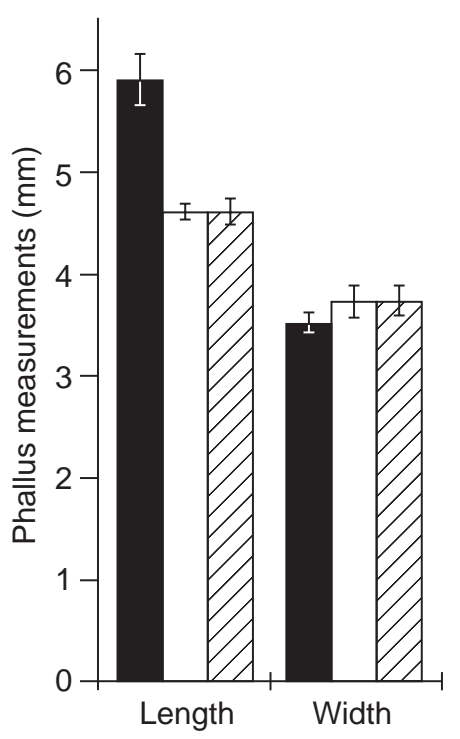

Fig. 3. The length and width of the phallus (mean \pm SEM) of control male $(n=6)(\square)$, control female $(n=6)(\square)$ and flutamidetreated male $(n=9)(\square)$ tammar wallabies.

cytoplasm and dark staining elliptical nuclei. The epithelium of the urethra consisted of stratified squamous epithelium similar to that of the prostatic buds.

The prostate gland of flutamide-treated males was smaller and less developed than that of control males (Fig. 2b). Although epithelial buds were present and projected ventrally, dorsally and laterally into the surrounding mesenchyme, there was significantly less bud formation, and only rarely were isolated buds observed in the mesenchyme, indicating that the buds were much shorter. Prostatic buds were present only in the cranial portion of the prostate gland and these buds did not have a patent lumen. The epithelium of both the buds and the urethra consisted of stratified squamous epithelium, with eosinophilic cytoplasm and dark staining elliptical nuclei. The prostatic urethra was larger than that of controls (Fig. 2).

\section{Morphology of the phallus}

In control males, the phalluses were well developed and projected out of the genital tubercle. The phalluses of flutamide-treated males were feminized, and were significantly shorter than those of control males $(P \leqslant 0.05)$, but were the same length as those of females (Fig. 3).

\section{Inguinal canal morphology and hernias}

The inguinal canal of control males had a distinctive hourglass shape, wide at the internal inguinal ring then constricting as it passed the pubic bone and expanding more distally. There was no significant fusion of the epithelial lining of the processus and, thus, the canal was patent along its entire length. The spermatic vessels were situated dorsally and under the peritoneal lining of the canal. More distally, the spermatic vessels expanded into a network of capillaries, the pampiniform plexus, and bulged away from the dorsal inguinal wall. Near the testis, the blood vessels were enclosed in a fold of peritoneum. The cremaster evenly surrounded the inguinal canal distally, but more proximally, near the internal inguinal ring, the cremaster extended lateral-dorsally from the canal forming the distinctive muscular strip seen in the adult.

Three of the nine flutamide-treated males had unilateral inguinal hernias on their right-hand side. In these animals, the intestine protruded through the inguinal canal and was situated at the neck of the scrotum. The earliest sign of an inguinal hernia was by day 36 after birth. The herniated gut could freely pass in and out of the inguinal canal, so an animal that had herniated gut in the inguinal canal on one day may not have $24 \mathrm{~h}$ later, but the hernia may recur later. Only one male had herniated gut in the inguinal canal at autopsy on day 75 after birth.

All of the flutamide-treated males examined, regardless of whether they had a hernia, had inguinal canals that formed an hourglass shape; however, the perimeter of the processus vaginalis was significantly larger in flutamidetreated than in control animals $(4420 \pm 376 \mu \mathrm{m}$ versus $3313 \pm 564 \mu \mathrm{m} ; P \leqslant 0.05)$. The spermatic vessels were situated dorsally under the peritoneal lining of the canal. The vessels expanded into a network of capillaries, the pampiniform plexus, and bulged out of the peritoneal layer into the distal portion of the inguinal canal. In all the flutamide-treated males examined, the cremaster muscle evenly surrounded the canal distally, but projected lateraldorsally near the internal inguinal ring.

\section{Expression of CGRP}

CGRP immunoreactivity was present in the L1 sensory neurones and dorsal root ganglia of tammar wallabies at all ages examined (days 65-100). CGRP immunoreactivity was found in both the cytoplasm of the axons and cell bodies of the neuronal cells. Intensity varied from light granular staining of the Golgi apparatus to intense staining of the whole cytoplasm (Fig. 4).

The L1 dorsal root ganglia of day 60 male and female pouch young showed specific DAPI-labelled genitofemoral nerve cell bodies. CGRP immunoreactivity was present in both the genitofemoral nerve and non-genitofemoral nerve cell bodies. Owing to technical difficulties, DAPI labelling of the genitofemoral nerve of males and females at day 75 after birth was unsuccessful. CGRP was localized within the L1 dorsal root ganglia of day 75 males, females and flutamidetreated males. CGRP was expressed in significantly more cell bodies of the L1 dorsal root ganglia in males than in females $(P \leqslant 0.05)$ (Fig. 5). Flutamide treatment significantly reduced the number of CGRP-positive cell bodies in the L1 dorsal root ganglia $(P \leqslant 0.05)$ (Fig. 5).

\section{Discussion}

Flutamide is a potent anti-androgen in tammar wallabies. Treatment from day 9 to day 75 inhibited virilization of the 


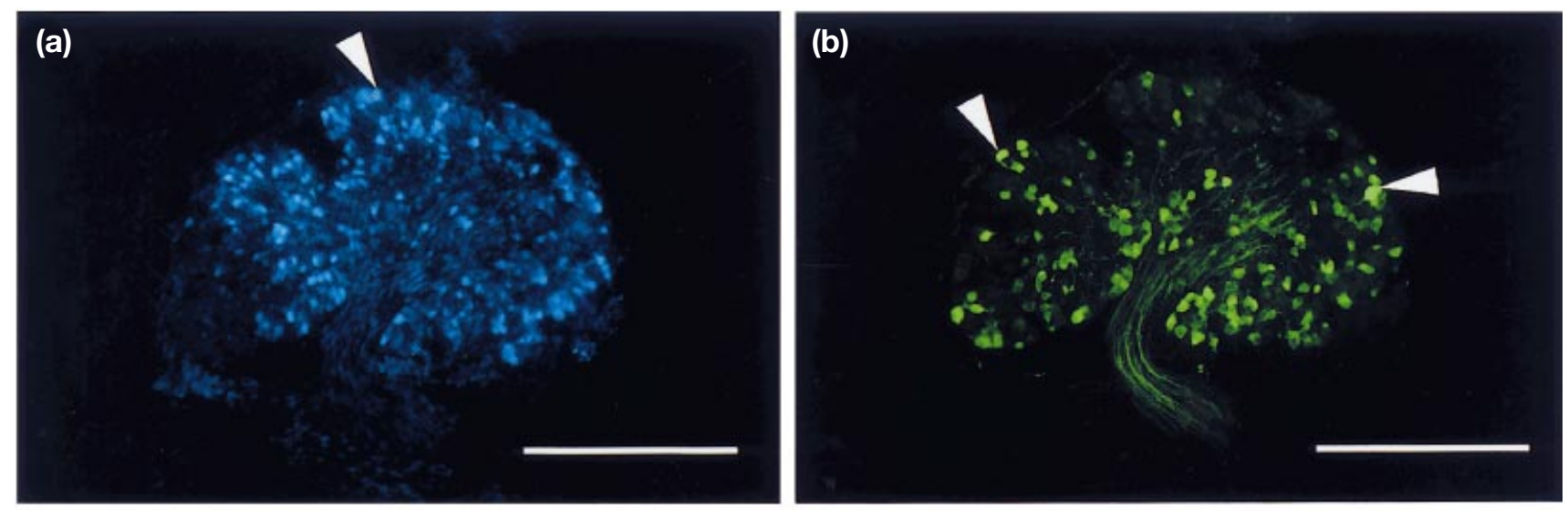

(c)

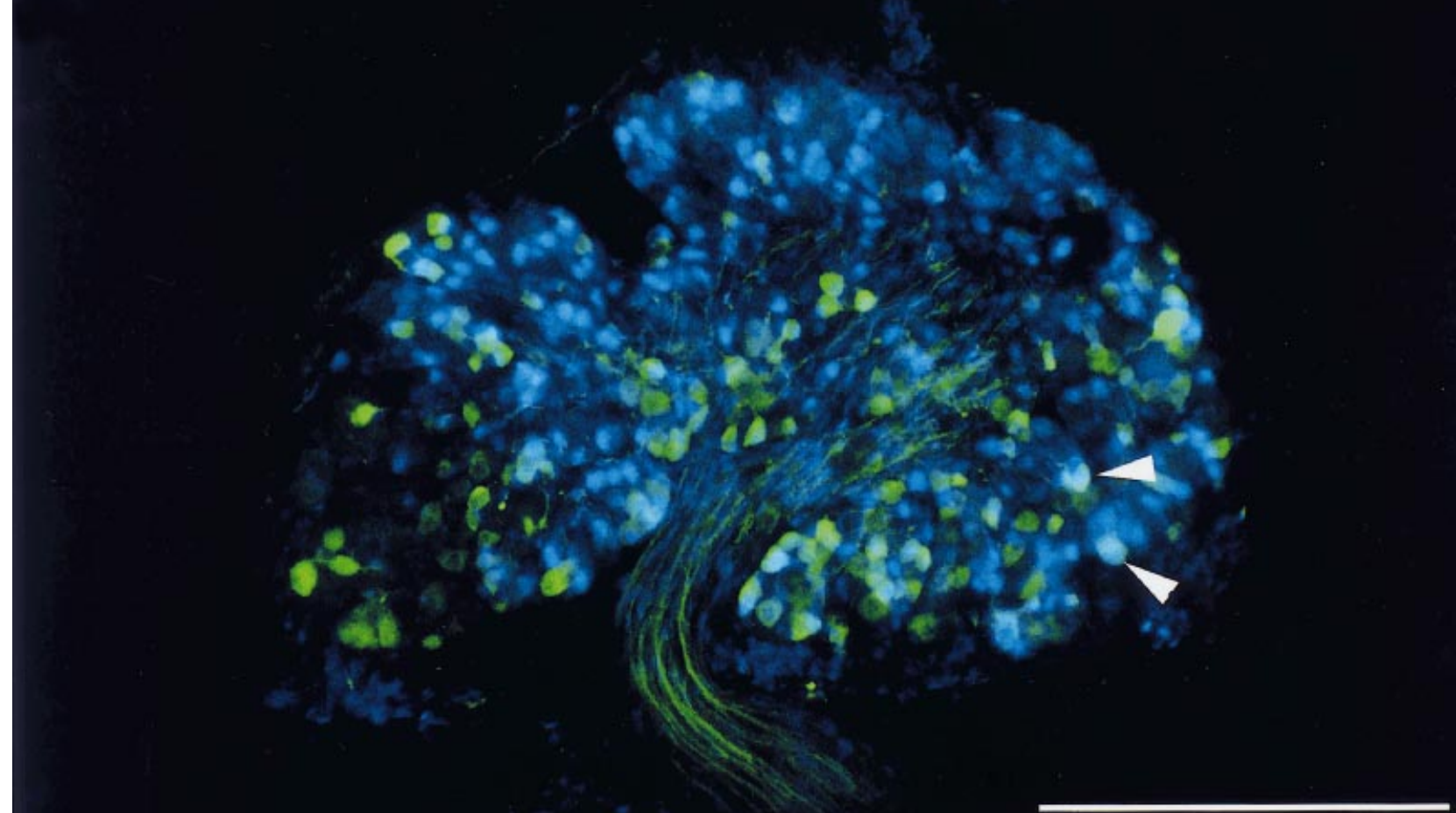

Fig. 4. (a) Retrograde fluorescent labelling (blue) of the genitofemoral nerve sensory nucleus (arrowhead) in a day 65 male pouch young tammar wallaby. (b) Calcitonin gene-related peptide (CGRP) immunofluorescent labelling (green) of the same section in which the CGRP was clearly localized to the cytoplasm and axons of the dorsal root cell bodies (arrowheads). (c) Both sections are super-imposed on top of each other to show the co-localization of the genitofemoral nerve cell bodies and the CGRP localized cell bodies (arrowheads). Scale bars represent $500 \mu \mathrm{m}$.

prostate gland and phallus, demonstrating that an effective anti-androgenic dose was administered, and led to a high incidence of inguinal hernia. It also led to a decrease in CGRP neurones in the L1 dorsal root ganglion, the source of the genitofemoral nerve. However, this treatment failed to inhibit testicular descent, indicating that androgens are not essential for this process in tammar wallabies.

The treatment with flutamide was anti-androgenic and it significantly inhibited the development of the prostate gland, a known androgen-dependent structure (George et al., 1985; Lucas et al., 1997; Butler et al., 1998). The significant difference in the length of the phallus between male and female tammar wallabies at day 75 after birth is consistent with observations of Leihy et al. (2002) and shows that penile growth in male tammar pouch young is dependent on androgen exposure between day 9 and day 75 after birth. As in eutherians, the developing phallus of marsupials contains androgen receptors (Butler et al., 1998) 


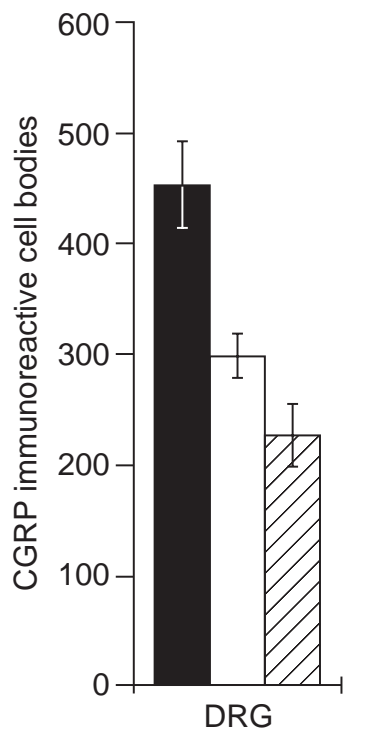

Fig. 5. (a) Number of calcitonin gene-related peptide (CGRP)positive cell bodies (mean \pm SEM) in the lumbar 1 dorsal root ganglia (DRG) of control male ( $\square$ ), control female $(\square)$ and flutamide-treated male $(\square)$ tammar wallabies.

and $5 \alpha$-reductase activity in the phallus is significantly higher than in non-androgen dependent tissues during the period of penis differentiation (George et al., 1985; Renfree et al., 1992; Shaw et al., 2000). Furthermore, androgen administration to opossums and tammar wallabies induces male-like differentiation of the phallus (Burns, 1961; Leihy et al., 2002). In tammar wallabies, the circulating androgen appears to be $5 \alpha$-androstane- $3 \alpha, 17 \beta$-diol (adiol) rather than testosterone and dihydrotestosterone (Shaw et al., 2000b; Wilson et al., 2002).

Despite the anti-androgenic effects of flutamide on the prostate gland and phallus, the development of the Wolffian duct into epididymis and vas deferens was not affected, which was also demonstrated by Lucas et al. (1997). Wolffian duct development in tammar wallabies is most sensitive to androgen exposure in the first 10 days after birth (Tyndale-Biscoe and Hinds, 1989; Coveney et al., 2002b).

Testicular descent in tammar wallabies, as in eutherians, occurs in two phases. Transabdominal migration occurs between day 10 and day 25 after birth, in which the testis comes to lie near the internal inguinal ring as a result of gubernacular enlargement, and inguinoscrotal migration between day 25 and day 60 after birth, during which the gubernaculum regresses and the testis passes into the scrotum (Hutson et al., 1988b; Renfree et al., 1996). The anatomy and timing of testicular descent in tammar wallabies differs from that of eutherian mammals. In eutherians, the tip of the gubernaculum is situated at the external inguinal ring and migrates into the scrotum during inguinoscrotal descent (Heyns, 1987; Fallat et al., 1992; Lam et al., 1998). Gubernacular migration appears to be mediated by androgens as flutamide treatment inhibits inguinoscrotal descent (Husmann and McPaul, 1991a; Shono et al., 1994; Cain et al., 1995). In tammar wallabies, the scrotum is situated cranial to the phallus, adjacent to the external inguinal ring and, thus, the distance for inguinoscrotal descent is significantly shorter than for eutherian mammals (Griffiths et al., 1993). Furthermore, the tip of the gubernaculum is positioned within the scrotum by day 0 after birth, before testis differentiation and inguinoscrotal descent (O et al., 1988), so it is unlikely that androgendependent gubernaculum migration occurs in this species. Consequently, the extension of the gubernaculum into the scrotum appears to play a minor role in inguinoscrotal descent in tammar wallabies (Griffiths et al., 1993) and the failure of flutamide to affect this phase of descent is consistent with this hypothesis.

Testicular descent and gubernacular development are dependent upon testicular hormones (Hutson et al., 1988b, 1997). Treatment of eutherians with flutamide prevents testicular descent (Hutson et al., 1997), but flutamide treatment from day 9 to day 45 after birth in tammar wallabies had no influence on testicular migration (Lucas et al., 1997). However, as testicular descent is not complete by day 45 after birth, effects on inguinoscrotal descent would not have been detected. Surprisingly, flutamide treatment at day 75 failed to affect the normal descent of the testis, indicating that androgens are not needed for testicular descent in this species. In eutherians, androgens affect gubernacular morphology and are necessary for gubernacular elongation from the abdominal wall to the scrotum (Hutson et al., 1994; Shono et al., 1994; Cain et al., 1995). However, the gubernaculum of tammar wallabies has already reached the neck of the scrotum by the day of birth (O et al., 1988).

Although flutamide did not inhibit testicular descent in tammar wallabies, $33 \%$ of flutamide-treated males had inguinal hernias. Inguinal hernias have been observed in previous studies. Flutamide treatment between day 9 and day 45 after birth caused inguinal hernias in $75 \%$ of flutamidetreated animals (Lucas et al., 1997). Likewise, 32\% of male tammar wallabies treated with oestrogen from day 0 to day 25 and from day 10 to day 25 after birth had inguinal hernias (Renfree et al., 2001; Coveney et al., 2002b). In all the flutamide-treated animals, the inguinal canal was enlarged irrespective of whether the animals developed a hernia. Therefore, these studies indicate that androgens are essential for normal closure of the inguinal canal in tammar wallabies.

The effects of androgen on inguinoscrotal testicular descent and inguinal closure may be mediated through CGRP neurones in the genitofemoral nerve (Hutson et al., 1997). In humans, abnormalities in the genitofemoral nerve are linked to defects of testicular descent (Clarnette and Hutson, 1996). In rats, androgens increase the number of genitofemoral nerve cell bodies within the spinal nuclei and the expression of CGRP within these cell bodies (Larkins et al., 1991; Schwindt et al., 1999; Hrabovszky et al., 2000). CGRP induces contraction of the rodent gubernaculum in culture and this contraction is thought to direct the gubernaculum and testis towards the scrotum (Park and Hutson, 1991). The lower numbers of CGRP neurones in 
females and flutamide-treated males may prevent gubernacular orientation and descent of the testis (Hrabovszky et al., 2000). In keeping with the lack of effect of androgens on testicular descent in tammar wallabies, the tammar gubernaculum has relatively little muscle (Griffiths et al., 1993; Coveney et al., 2002a) and CGRP did not stimulate twitching of tammar gubernaculum in vitro (Griffiths et al., 1993).

In humans, abnormalities in the genitofemoral nerve are also associated with defects in inguinal closure, including inguinal hernia and scrotal hydroceles (Clarnette and Hutson, 1996). CGRP causes epithelial obliteration in human hernial sacs in culture (Hutson et al., 2000). In tammar wallabies, CGRP was present within the genitofemoral nerve cell bodies of male and female pouch young at day 60 after birth, and day 75 males had significantly more CGRP immunoreactive cell bodies than did females. This sexual dimorphism in numbers of CGRP neurones appears to be androgen dependent, as flutamide-treated males had significantly fewer CGRP cell bodies than did control males.

Although it is unlikely that CGRP has a role in testicular descent in tammar wallabies, it may be involved in subsequent inguinal closure. As in humans, the inguinal canal goes through a process of closure after descent, but the extent of closure differs between the two species (Coveney et al., 2002a). In humans, there is complete epithelial loss and fusion of the processus vaginalis, which appears to be androgen dependent, as closure fails in patients with androgen resistance (Atwell, 1961, 1962). In male tammar wallabies, the inguinal canal closes, via a reduction in processus vaginalis size, only persisting as a small lumen, a situation similar to that seen in inguinal hydrocele in humans (Coveney et al., 2002a). As in humans, inguinal closure appears to be mediated by androgen as flutamide treatment inhibits inguinal closure and leads to a high incidence of inguinal hernia (Lucas et al., 1997; this study).

The observations in the present study that flutamide treatment in tammar wallabies decreased the number of CGRP neurones, as well as predisposing to inguinal hernia is consistent with the hypothesis that androgens induce inguinal closure via CGRP. The results of the present study also demonstrate that testicular descent can proceed in the absence of androgens in this species.

The authors thank D. Mattiske, A. Pask, M. Leihy, S. Brownlees and J. Akamatis for help in animal handling. The authors also thank B. Cook, C. Anderson and P. Farmer for their technical support with immunohistochemistry. Animals were collected under permits from South Australian National Parks and Wildlife, and held under permit number RP-95-088 of the Department of Natural Resources and Environment, Victoria. This study was funded by grants from the National Health and Medical Research Council of Australia.

\section{References}

Atwell JD (1961) Inguinal herniae and the testicular feminization syndrome in infancy and childhood British Journal of Surgery 49 367-371

Atwell JD (1962) Inguinal hernia in female infants and children British Journal of Surgery 50 294-297
Barthold JS, Kumasi-Rivers K, Upadhyay J, Shekarriz B and ImperatoMcGinley J (2000) Testicular position in the androgen insensitivity syndrome: implications for the role of androgens in testicular descent Journal of Urology 164 497-501

Beasley SW and Hutson JM (1987) Effect of division of genitofemoral nerve on testicular descent in the rat Australian and New Zealand Journal of Surgery 57 49-51

Bentvelsen FM and George FW (1993) The fetal rat gubernaculum contains higher levels of androgen receptor than does the postnatal gubernaculum Journal of Urology 150 1564-1566

Burns RK (1939a) The differentiation of sex in the opossum (Didelphys virginiana) and its modification by male hormone testosterone propionate Journal of Morphology 65 79-119

Burns RK (1939b) Effects of testosterone propionate on sex differentiation in pouch young of opossum Proceedings of the Society of Experimental Biology and Medicine 41 60-62

Burns RK (1939c) Sex differentiation during the early pouch stages of the opossum (Didelphys virginiana) and a comparison of the anatomical changes induced by male and female sex hormones Journal of Morphology 65 497-547

Burns RK (1961) Role of hormones in the differentiation of sex. In Sex and Internal Secretions pp 76-158 Ed. WC Young. Williams and Wilkins, Baltimore

Butler CM, Harry JL, Deakin JE, Cooper DW and Renfree MB (1998) Developmental expression of the androgen receptor during virilization of the urogenital system of a marsupial Biology of Reproduction $\mathbf{5 9}$ 725-732

Butler CM, Shaw G and Renfree MB (1999) Development of the penis and clitoris in the tammar wallaby, Macropus eugenii. Anatomy and Embryology 199 451-457

Cain MP, Kramer SA, Tindall DJ and Husmann DA (1995) Flutamideinduced cryptorchidism in the rat is associated with altered gubernacular morphology Urology 46 553-558

Clarnette TD and Hutson JM (1996) The genitofemoral nerve may link testicular inguinoscrotal descent with congenital inguinal hernia Australian and New Zealand Journal of Surgery 66 612-617

Clarnette TD and Hutson JM (1999) The development and closure of the processus vaginalis Hernia 3 97-102

Clarnette TD, Hutson JM and Beasley SW (1996) Factors affecting the development of the processus vaginalis in the rat Journal of Urology 156 1463-1466

Coveney D, Shaw G, Hutson JM and Renfree MB (2002a) The development of the gubernaculum and inguinal closure in the marsupial Macropus eugenii. Journal of Anatomy $201239-256$

Coveney D, Shaw G and Renfree MB (2002b) Effects of oestrogen treatment on testicular descent, inguinal closure and prostatic development in a male marsupial Reproduction 124 73-83

Emmen JM, McLuskey A, Grootegoed JA and Brinkmann AO (1998) Androgen action during male sex differentiation includes suppression of cranial suspensory ligament development Human Reproduction 13 $1272-1280$

Fallat ME, Williams MPL, Farmer PJ and Hutson JM (1992) Histological evaluation of inguinoscrotal migration of the gubernaculum in rodents during testicular descent and its relationship to the genitofemoral nerve Pediatric Surgery International 7 265-270

Fentener van Vlissingen JM, Blankenstein MA, Thijssen JH, Colenbrander B, Verbruggen AJ and Wensing CJ (1988) Familial male pseudohermaphroditism and testicular descent in the racoon dog (Nyctereutes) Anatomical Record 222 350-356

George FW, Hodgins MB and Wilson JD (1985) The synthesis and metabolism of gonadal steroids in pouch young of the opossum, Didelphis virginiana. Endocrinology 116 1145-1150

Griffiths AL, Renfree MB, Shaw G, Watts LM and Hutson JM (1993) The tammar wallaby (Macropus eugenii) and the Sprague-Dawley rat: comparative anatomy and physiology of inguinoscrotal testicular descent Journal of Anatomy 183 441-450

Heyns CF (1987) The gubernaculum during testicular descent in the human fetus Journal of Anatomy 153 93-112

Heyns CF and Pape VC (1991) Presence of a low capacity androgen 
receptor in the gubernaculum of the pig fetus Journal of Urology 145 $161-167$

Hrabovszky Z, Farmer PJ and Hutson JM (2000) Does the sensory nucleus of the genitofemoral nerve have a role in testicular descent? Journal of Pediatric Surgery 35 96-100

Humason GL (1962) Animal tissue techniques W. H. Freeman and Co., San Francisco

Husmann DA and McPhaul MJ (1991a) Time-specific androgen blockade with flutamide inhibits testicular descent in the rat Endocrinology 129 1409-1416

Husmann DA and McPhaul MJ (1991b) Localization of the androgen receptor in the developing rat gubernaculum Endocrinology $\mathbf{1 2 8}$ 383-387

Hutson JM (1985) A biphasic model for the hormonal control of testicular descent Lancet 2 419-421

Hutson JM (1986) Testicular feminization: a model for testicular descent in mice and men Journal of Pediatric Surgery 21 195-198

Hutson JM, Beasley SW and Bryan AD (1988a) Cryptorchidism in spina bifida and spinal cord transection: a clue to the mechanism of transinguinal descent of the testis Journal of Pediatric Surgery 23 275-277

Hutson JM, Shaw G, O WS, Short RV and Renfree MB (1988b) Müllerian inhibiting substance production and testicular migration and descent in the pouch young of a marsupial Development 104 549-556

Hutson JM, Baker M, Terada M, Zhou B and Paxton G (1994) Hormonal control of testicular descent and the cause of cryptorchidism Reproduction, Fertility and Development 6 151-156

Hutson JM, Hasthorpe S and Heyns CF (1997) Anatomical and functional aspects of testicular descent and cryptorchidism Endocrine Reviews 18 259-280

Hutson JM, Albano FR, Paxton G, Sugita Y, Connor R, Clarnette TD, Gray AZ, Watts LM, Farmer PJ and Hasthorpe S (2000) In vitro fusion of human inguinal hernia with associated epithelial transformation Cells Tissues Organs 166 249-258

Johansen TE and Klein H (1993) Evidence of androgen receptivity in the pathway of testicular descent in humans: a postnatal study European Urology 23 466-468

Jurgelski W, Jr (1971) Administration of test materials to the neonatal North American opossum (Didelphys marsupialis virginiana Kerr) Laboratory Animal Science 21 748-751

Lam SK, Clarnette TD and Hutson JM (1998) Does the gubernaculum migrate during inguinoscrotal testicular descent in the rat? Anatomical Record 250 159-163

Larkins SL, Hutson JM and Williams MPL (1991) Localisation of calcitonin gene-related peptide immunoreactivity within the spinal nucleus of the genitofemoral nerve Pediatric Surgery International 6 176-179

Lee SM and Hutson JM (1999) Effect of androgens on the cranial suspensory ligament and ovarian position Anatomical Record 255 306-315

Leihy MW, Shaw G, Wilson JD and Renfree MB (2001) Virilization of the urogenital sinus of the tammar wallaby is not unique to $5 \alpha$-androstane$3 \alpha, 17 \beta$-diol Molecular and Cellular Endocrinology 181 111-115

Leihy MW, Shaw G, Renfree MB and Wilson JD (2002) Administration of $5 \alpha$-androstane- $3 \alpha, 17 \beta$-diol to female tammar wallaby pouch young causes development of a mature prostate and male urethra Endocinology $1432643-2651$

Lewis LG (1948) Cryptorchidism Journal of Urology 60 345-356

Lucas JC, Renfree MB, Shaw G and Butler CM (1997) The influence of the anti-androgen flutamide on early sexual differentiation of the marsupial male Journal of Reproduction and Fertility 109 205-212

O W-S, Short RV, Renfree MB and Shaw G (1988) Primary genetic control of somatic sexual differentiation in a mammal Nature 331 716-717

Park WH and Hutson JM (1991) The gubernaculum shows rhythmic contractility and active movement during testicular descent Journal of Pediatric Surgery 26 615-617

Poole WE, Simms NG, Wood JT and Lubulwa M (1991) Tables for age determination of the Kangaroo Island wallaby (Tammar), Macropus eugenii, from body measurements. CSIRO Technical Memorandum 32, CSIRO Division of Wildlife and Ecology, Canberra, Australia

Renfree MB and Short RV (1988) Sex determination in marsupials: evidence for a marsupial-eutherian dichotomy Philosophical Transactions of the Royal Society of London Series B Biological Sciences 322 41-53

Renfree MB, Coveney D and Shaw G (2001) The influence of estrogen on the developing male marsupial Reproduction, Fertility and Development 13 231-240

Renfree MB, O WS, Short RV and Shaw G (1996) Sexual differentiation of the urogenital system of the fetal and neonatal tammar wallaby, Macropus eugenii. Anatomy and Embryology 194 111-134

Renfree MB, Wilson JD, Short RV, Shaw G and George FW (1992) Steroid hormone content of the gonads of the tammar wallaby during sexual differentiation Biology of Reproduction 47 644-647

Ryhorchuk AR, Shaw G, Butler CM and Renfree MB (1997) Effects of a $5 \alpha$ reductase inhibitor, finasteride, on the developing prostate and testis of a marsupial Journal of Andrology 18 123-130

Schwindt B, Farmer PJ, Watts LM, Hrabovszky Z and Hutson JM (1999) Localization of calcitonin gene-related peptide within the genitofemoral nerve in immature rats Journal of Pediatric Surgery 34 986-991

Shaw G, Renfree MB, Short RV and O WS (1988) Experimental manipulation of sexual differentiation in wallaby pouch young treated with exogenous steroids Development 104 689-701

Shaw G, Renfree MB, Leihy MW, Shackleton CH, Roitman E and Wilson JD (2000) Prostate formation in a marsupial is mediated by the testicular androgen $5 \alpha$-androstane- $3 \alpha, 17 \beta$-diol Proceedings National Academy of Science USA 9712 256-12 259

Shono T, Ramm-Anderson S, Goh DW and Hutson JM (1994) The effect of flutamide on testicular descent in rats examined by scanning electron microscopy Journal of Pediatric Surgery 29 839-844

Tayakkanonta K (1963) The gubernaculum testis and its nerve supply The Australian and New Zealand Journal of Surgery 33 61-67

Tyndale-Biscoe CH and Hinds LA (1989) Influence of the immature testis on sexual differentiation in the tammar wallaby, Macropus eugenii (Macropodidae: Marsupialia) Reproduction, Fertility and Development 1 243-254

Tyndale-Biscoe CH and Renfree MB (1987) Reproductive Physiology of Marsupials Cambridge University Press, Cambridge

van der Schoot P (1993) Doubts about the 'first phase of testis descent' in the rat as a valid concept Anatomy and Embryology 187 203-208

van der Schoot P and Elger W (1992) Androgen-induced prevention of the outgrowth of cranial gonadal suspensory ligaments in fetal rats Journal of Andrology 13 534-542

Wensing CJ (1973) Testicular descent in some domestic mammals. 3. Search for the factors that regulate the gubernacular reaction Proceedings of the Koninklijke Nederlandse Akademie van Wetenschappen Series C Biological and Medical Science 76 196-202

Wensing CJG, Colenbrander B and Bosma A (1975) Testicular feminization syndrome and the gubernacular development in the pig Proceedings of the Koninklijke Nederlandse Akademie van Wetenschappen Series C Biological and Medical Science 78 402-405

Wilson JD, George FW, Shaw G and Renfree MB (1999) Virilization of the male pouch young of the tammar wallaby does not appear to be mediated by plasma testosterone or dihydrotestosterone Biology of Reproduction 61 471-475

Wilson JD, Shaw G, Leihy MW and Renfree MB (2002) The marsupial model for male phenotypic development Trends in Endocrinology and Metabolism 13 78-83

Received 18 May 2002.

First decision 8 August 2002.

Revised manuscript received 20 August 2002.

Accepted 22 August 2002. 